\title{
Isolation of agarase-producing bacteria from seawater and examination of the enzyme activity
}

Lien T. H. Nguyen, Phong V. Nguyen, \& Thanh T. L. Bien*

Department of Biotechnology, Nong Lam University, Ho Chi Minh City, Vietnam

\section{ARTICLE INFO}

\section{Research Paper}

Received: September 20, 2019

Revised: December 17, 2019

Accepted: January 16, 2020

\section{Keywords}

\section{Agarase}

Agarolytic bacteria

Reducing sugar

Seaweed

Seawater

\section{${ }^{*}$ Corresponding author}

Bien Thi Lan Thanh

Email: bienthilanthanh@hcmuaf.edu.vn

\section{ABSTRACT}

This study aimed to isolate agarase-producing bacteria from seawater, and then determine activity of the agarase. Eight coastal surface seawater samples were collected from Ba Ria Vung Tau province. Twenty-one bacterial strains that are capable of liquefying agar were isolated. These isolates produced disintegration zones around their colonies on agar plates with diameters ranging from 4.0 to $7.0 \mathrm{~cm}$ after an incubation period of 2 days at room temperature. Five bacterial strains (M1, M5, M7, M62B, and M71) that produced large halos on plates were identified belonging to Vibrio genus with identity $>96 \%$. The crude enzyme activities of these strains ranged from 0.15 to $0.22 \mathrm{U} / \mathrm{mL}$ in reaction with agarose as substrate. Among isolated strains, the strain M71 showed the highest agarase activity, and was used to examine the degradation of seaweed. The hydrolysis of dried Gracilaria seaweed by the crude enzyme of M71 at concentration of $5 \%(\mathrm{v} / \mathrm{v})$ released 915 $\mu \mathrm{M} / \mathrm{mL}$ reducing sugar after a $24-\mathrm{h}$ incubation period at $40^{\circ} \mathrm{C}$.

Cited as: Nguyen, L. T. H., Nguyen, P. V., \& Bien, T. T. L. (2020). Isolation of agarase-producing bacteria from seawater and examination of the enzyme activity. The Journal of Agriculture and Development 19(2), 50-58. 


\title{
Phân lập vi khuẩn tổng hợp enzyme agarase từ nước biển và xác định hoạt tính của enzyme
}

\author{
Nguyễn Thị Hồng Liên, Nguyễn Vũ Phong \& Biện Thị Lan Thanh* \\ Bộ Môn Công Nghệ Sinh Học, Trường Đại Học Nông Lâm TP.HCM, TP. Hồ Chí Minh
}

\section{THÔNG TIN BÀI BÁO}

\section{Bài báo khoa học}

Ngày nhận: 20/09/2019

Ngày chỉnh sửa: 17/12/2019

Ngày chấp nhận: 16/01/2020

\section{Từ khóa}

Agarase

Đường khử

Nước biển

Rong biển

Vi khuẩn phân giải agar

\section{*Tác giả liên hệ}

Biện Thị Lan Thanh

Email: bienthilanthanh@hcmuaf.edu.vn

\section{TÓM TẮT}

Nghiên cứu này nhằm mục tiêu phân lập vi khuẩn có khả năng tổng hợp enzyme agarase từ nước biển và xác định hoạt tính của enzyme. Từ 8 mẫu nước biển thu thập tại các địa điểm khác nhau ở tỉnh Bà Rịa - Vũng Tàu, đã phân phập được 21 chủng vi khuẩn có khả năng phân giải agar trên đĩa thạch với đường kính vòng phân giải dao động từ 4,0 đến $7,0 \mathrm{~cm}$ sau 2 ngày ủ ở nhiệt độ phòng. Năm chủng vi khuẩn $(\mathrm{M} 1, \mathrm{M} 5, \mathrm{M} 7$, M62B, và M71) tạo đường kính vòng phân giải lớn nhất có hoạt độ enzyme agarase thô được xác định trong khoảng 0,15 - $0,22 \mathrm{U} / \mathrm{mL}$ khi phản ứng với cơ chất agarose, và có trình tự 16S rDNA tương đồng (>96\%) với chi Vibrio. Trong đó, chủng vi khuẩn M71 có hoạt tính agarase cao nhất và được dùng để đánh giá khả năng phân giải rong biển. Sự thủy phân rong đỏ Gracilaria bằng dịch enzyme thô của chủng M71 ở nồng độ $5 \%(\mathrm{v} / \mathrm{v})$ giải phóng $915 \mu \mathrm{M} / \mathrm{mL}$ đường khử sau 24 giờ ủ ở $40^{\circ} \mathrm{C}$.

\section{1. Đặt Vấn Đề}

Việt Nam có vùng biển nhiệt đới với bờ biển dài $3.260 \mathrm{~km}$, diện tích mặt nước khoảng 1 triệu $\mathrm{km}^{2}$, với sự đa dạng về các loài thủy sinh vật. Một trong những nguồn tài nguyên phong phú và đa dạng của vùng biển nước ta là rong biển. Tại Việt Nam, đã xác định được 800 loài rong biển thuộc 4 ngành: ngành rong đỏ (Rhodophyta) chiếm hơn 400 loài, ngành rong lục (Chlorophyta) chiếm 180 loài, ngành rong nâu (Phaeophyta) hơn 140 loài và ngành rong lam (Cyanophyta) gần 100 loài (Nguyen \& ctv., 1993). Rong biển chứa hàm lượng carbohydrate cao khoảng 50 - 60\% khối lượng khô và không chứa lignin nên rất dễ được thủy phân thành các dạng đường đơn dễ lên men (Rioux \& Turgeon, 2015). Trong đó, agar là một dạng polysaccharide phổ biến trong thành phần của rong đỏ. Agar có cấu trúc là một polymer của galactose có thể chuyển thành đường galactose và 3,6-anhydrogalactose (Usov, 2011). Quá trình lên men sản xuất ethanol từ sinh khối rong biển gồm hai giai đoạn chính: thủy phân nguyên liệu (đường hóa) và lên men. Thủy phân là quá trình chuyển hóa nguyên liệu thành các sản phẩm trung gian tan như các oligosaccharide và các đường đơn. Lên men là quá trình chuyển hóa các sản phẩm trung gian và các đường đơn thành ethanol bởi nấm men (Yanagisawa \& ctv., 2013).

Thủy phân nguyên liệu là bước đầu tiên và quan trọng trong sản xuất ethanol. Theo truyền thống, agar có thể được thủy phân bằng nhiệt hoặc acid loãng. Tuy nhiên, hai phương pháp này thường không an toàn do sử dụng acid và nhiệt độ cao, và không đạt hiệu quả thủy phân cao. Phương pháp thủy phân bằng sinh học (sử dụng enzyme agarase) đã được chứng minh là an toàn và cho hiệu suất thủy phân cao (Kawaroe \& ctv., 2017).

Enzyme agarase được chia thành hai nhóm $\alpha$-agarase (E.C. 3.2.1.158) và $\beta$-agarase (E.C. 3.2.1.81) dựa vào vị trí phân tách. Agarase được 
ứng dụng rộng rãi trong công nghiệp thực phẩm, mỹ phẩm và $\mathrm{y}$ học do khả năng tạo ra các oligosaccharides giá trị (Fu \& Kim, 2010). Lựa chọn được nguồn enzyme agarsase có hoạt tính cao có thể rút ngắn thời gian và tăng hiệu quả thủy phân, do đó làm tăng hiệu suất của quá trình lên men. Do đó, đề tài này được thực hiện nhằm mục đích phân lập, tuyển chọn và xác định hoạt tính các chủng vi khuẩn có khả năng sản xuất enzyme agarase từ nước biển để ứng dụng trong sản xuất ethanol từ rong biển.

\section{Vật Liệu và Phương Pháp Nghiên Cứu}

\subsection{Thu mẫu nước biển}

Tám mẫu nước biển được thu tại các địa điểm khác nhau ở xã Phước Tĩnh (3 mẫu) và thị trấn Long Hải (5 mẫu), tỉnh Bà Rịa - Vũng Tàu. Mẫu nước biển được thu cách bề mặt khoảng $5 \mathrm{~cm}$, chứa trong các chai nhựa sạch, được trữ lạnh (< $10^{\circ} \mathrm{C}$ ) và phân tích trong vòng 24 giờ.

\subsection{Tăng sinh vi khuẩn}

Môi trường tăng sinh được sử dụng là $100 \mathrm{~mL}$ nước biển có bổ sung $0,1 \%(\mathrm{w} / \mathrm{v})$ agar (Agbo \& Moss, 1979) trong các chai thủy tinh $250 \mathrm{~mL}$ và hấp khử trùng ở $121^{\circ} \mathrm{C}$ trong 15 phút. Một mL nước biển ở mỗi mẫu được ủ trong các chai môi trường ở nhiệt độ phòng trong 5 ngày.

\subsection{Phân lập vi khuẩn phân giải agar}

Dịch tăng sinh vi khuẩn được pha loãng thành dãy nồng độ $10^{-1}$ dến $10^{-3}$. Sau đó, $0,1 \mathrm{~mL}$ dung dịch ở mỗi nồng độ được cấy trãi trên các đĩa môi trường ZoBell Marine agar (Himedia, India), mỗi nồng độ cấy 3 đĩa, và ủ ở nhiệt độ phòng trong 5 ngày. Các khuẩn lạc có khả năng hóa lỏng (làm mềm) agar trên đĩa thạch được chọn lọc, làm thuần và nhuộm Gram quan sát hình dạng tế bào dưới kính hiển vi. Các chủng vi khuẩn phân lập được bảo quản trong glycerol $20 \%$ và trữ ở $-20^{\circ} \mathrm{C}$ cho các thí nghiệp tiếp theo.

\subsection{Khảo sát hoạt tính phân giải agar của các chủng vi khuẩn phân lập}

Khả năng phân giải agar của các chủng vi khuẩn phân lập được xác định dựa vào đường kính vòng phân giải agar trên đĩa thạch. Vi khuẩn được tăng sinh qua đêm trong môi trường Ma- rine broth ở nhiệt độ phòng. Hút $10 \mu \mathrm{L}$ dịch vi khuẩn nhỏ vào bề mặt môi trường Marine agar và ủ ở nhiệt độ phòng trong 2 ngày. Sau khi ủ, các đĩa được nhuộm với dung dịch Lugol iodine trong 10 phút và quan sát vòng phân giải agar (vòng sáng hình thành trên nền tối của thuốc nhuộm) xung quanh khuẩn lạc (Agbo \& Moss, 1979). Vòng phân giải agar (A) được xác định theo công thức: $\mathrm{A}(\mathrm{cm})=\mathrm{D}-\mathrm{d}$, trong đó $\mathrm{D}$ là đường kính vòng sáng và $\mathrm{d}$ nhỏ là đường kính khuẩn lạc.

\section{5. Định danh các chủng vi khuẩn có khả năng phân giải agar mạnh}

Các chủng vi khuẩn có đường kính vòng phân giải lớn trên đĩa thạch được chọn để định danh bằng cách giải trình tự vùng gene $16 \mathrm{~S}$ rRNA. DNA tổng số của vi khuẩn được ly trích với GeneJET Genomic DNA Purification Kit (Thermo Scientific) theo hướng dẫn của nhà sản xuất. Đoạn gene $16 \mathrm{~S}$ rRNA được khuếch đại bằng $\mathrm{PCR}$ với cặp primer 27F (5'AGAGTTTGATCCTGGCTCAG-3') và 1492R (5'-GGTTACCTTGTTACGACTT-3') (Lane, 1991). Thành phần phản ứng $(50 \mu \mathrm{L})$

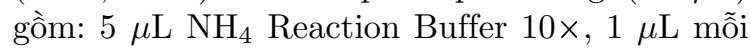
primer $0,5 \mathrm{mM}, 3 \mu \mathrm{L} \mathrm{MgCl}_{2}, 0,5 \mu \mathrm{L}$ dNTP Mix $100 \mathrm{mM}, 1 \mu \mathrm{L}$ BIOTAQ, $2 \mu \mathrm{L}$ DNA mẫu và $36,5 \mu \mathrm{L}$ nước cất khử trùng. PCR được thực hiện bởi máy Thermal Cycler 2720 (Applied Biosystems $^{\top \mathrm{M}}$ ) với chu trình nhiệt: tiền biến tính ở $94^{\circ} \mathrm{C}$ trong 3 phút, sau đó 35 chu kì bao gồm $94^{\circ} \mathrm{C}$ trong 30 giây, $55^{\circ} \mathrm{C}$ trong 30 giây, và $72^{\circ} \mathrm{C}$ trong 1 phút. Sản phẩm PCR (khoảng 1.500 $\mathrm{bp)}$ được kiểm tra bằng cách điện di trên gel agarose $1,5 \%$ và giải tự bởi Công ty Cổ phần Kỹ thuật và Sinh học ứng dụng Việt Nam. Trình tự $16 \mathrm{~S}$ rDNA của các chủng vi khuẩn tuyển chọn sau đó được so sánh độ tương đồng với các trình tự đã biết trên ngân hàng gene (http://blast.ncbi.nlm.nih.gov/Blast.cgi).

\subsection{Xác định hoạt độ enzyme agarase}

Hoạt độ enzyme agarase của các chủng vi khuẩn tuyển chọn được xác định thông qua lượng đường khử được giải phóng khi phản ứng với cơ chất agarose (Faturrahman \& ctv., 2011). Vi khuẩn được tăng sinh 2 ngày trong môi trường Marine broth và sau đó ly tâm ở $8500 \times \mathrm{g}, 4^{\circ} \mathrm{C}$ trong 20 phút để loại bỏ tế bào. Hút $1 \mathrm{~mL}$ dịch sau ly tâm (dịch enzyme thô) trộn đều với $1 \mathrm{~mL}$ 
dung dịch agarose $0,2 \%(\mathrm{w} / \mathrm{v}$, được pha với dung dịch đệm Tris- $\mathrm{HCl} 50 \mathrm{mM}, \mathrm{pH} 7,0)$ và $1 \mathrm{~mL}$ dung dịch Tris- $\mathrm{HCl} 50 \mathrm{mM}(\mathrm{pH} 7,0)$, ủ ở $40^{\circ} \mathrm{C}$ trong 15 phút. Lượng đường khử được giải phóng sau phản ứng được xác định bằng phương pháp 3,5dinitrosalicylic acid (DNS) dựa vào đường chuẩn glucose (Miller, 1959). Hoạt độ enzyme agarase (U) được xác định là lượng enzyme cần thiết để giải phóng $1 \mu \mathrm{M}$ đường khử khi phản ứng với cơ chất agarose trong 1 phút và được thể hiện với đơn vị $\mathrm{U} / \mathrm{mL}$ cơ chất.

\section{7. Đánh giá khả năng thủy phân rong biển của enzyme agarase từ vi khuẩn}

Chủng vi khuẩn sinh enzyme agarase có hoạt độ cao nhất được chọn để đánh giá khả năng thủy phân rong biển theo phương pháp của (Kawaroe \& ctv., 2014). Dịch enzyme thô từ vi khuẩn sau 2 ngày tăng sinh trong môi trường Marine broth được thu nhận bằng cách ly tâm loại bỏ tế bào. Cơ chất là rong đỏ Gracilaria sp. khô được xay mịn và thêm $100 \mathrm{~mL}$ dung dịch đệm và hấp ở $121^{\circ} \mathrm{C}$ trong 15 phút. Sau khi làm nguội, dung dịch cơ chất được bổ sung dịch enzyme agarase thô ở nồng độ $5 \%, 10 \%$ và $15 \%(\mathrm{v} / \mathrm{v})$ và ủ ở $40^{\circ} \mathrm{C}$ trong 24 giờ. Lượng đường khử giải phóng sau phản ứng được xác định bằng phương pháp DNS với đường chuẩn glucose (Miller, 1959).

\subsection{Phân tích số liệu}

Tất cả các thí nghiệm đều được lặp lại ba lần và kết quả được biểu diễn dạng trung bình và độ lệch chuẩn $( \pm \mathrm{SD})$. Các số liệu được phân tích bằng phần mềm Minitab 16 và Excel 2013. Sự khác biệt giữa các trung bình được phân tích oneway ANOVA và trắc nghiệm phân hạng Duncan ở mức ý nghĩa $\alpha=0,05$.

\section{Kết Quả và Thảo Luận}

\subsection{Kết quả phân lập vi khuẩn phân giải agar}

Hai mươi mốt khuẩn lạc có khả năng phân hóa lỏng/làm mềm agar trên đĩa thạch (Hình 1) đã được phân lập từ tám mẫu nước biển thu thập ở các vùng biển xã Phước Tĩnh và thị trấn Long Hải, tỉnh Bà Rịa - Vũng Tàu. Các vi khuẩn phân lập có khuẩn lạc màu trắng đục, trắng ngà hoặc vàng nhạt, bờ đều, tế bào có hình ovan, que ngắn hoặc que cong và đều là vi khuẩn Gram âm (Bảng $1)$.

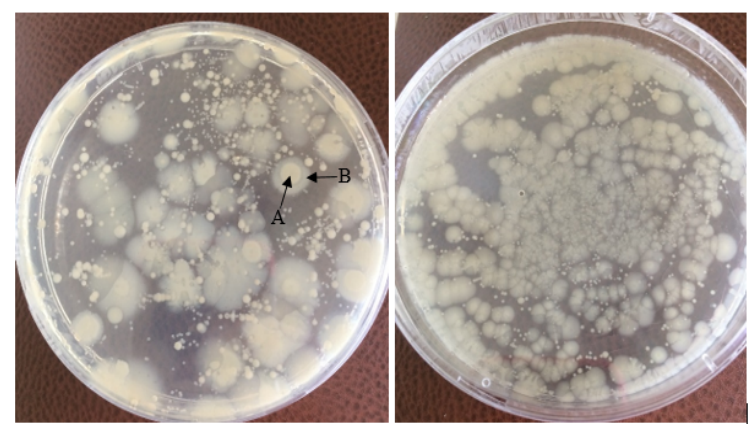

Hình 1. Các vi khuẩn phân giải agar sau 5 ngày phân lập trên môi trường Marine agar. A: khuẩn lạc vi khuẩn, B: agar xung quanh khuẩn lạc bị hóa lỏng/làm mềm.

Agar là một polysaccharide được sản xuất bởi hầu hết các loại tảo/rong đỏ trong môi trường biển, và ở đó có sự xuất hiện của các vi khuẩn phân giải agar (Zhang \& Kim, 2008). Vi khuẩn phân giải agar là những vi khuẩn sử dụng agar như là nguồn carbon và năng lượng. Trước đây, đã có nhiều nghiên cứu chứng minh vi khuẩn phân giải agar được phân lập từ các môi trường biển (Oh \& ctv., 2010; Thulasidas, 2012; Liu \& ctv., 2019).

Kết quả này phù hợp với công bố trước đây của Kolhatkar \& Sambrani (2018), ba chủng vi khuẩn phân giải agar có khuẩn lạc có màu trắng ngà và vàng nhạt, có tế bào hình que và dấu phẩy đã được phân lập từ mẫu nước ở biển Arabian. Các chủng vi khuẩn này được xác định là $A l$ teromonas marina SW-47(T), Vibrio alginolyticus và Pseudomonas stutzeri. Tương tự, González \& ctv. (2018) cũng đã phân lập được các chủng phẩy khuẩn sinh agarase gồm $V$. neocaledonicus và $V$. azureus từ tảo biển Ulva lactuca.

\subsection{Hoạt tính phân giải agar của các chủng vi khuẩn phân lập}

Trên môi trường thạch, các vi khuẩn sinh enzyme agarase phân giải agar xung quanh khuẩn lạc thành các oligosaccharide và đường Dgalactose. Do đó vùng agar xung quanh khuẩn lạc bị mềm hoặc hóa lỏng và lõm xuống, và sẽ không bắt màu nâu khi nhuộm với dung dịch Lugol tạo vùng sáng (Agbo \& Moss, 1979) (Hình 2). Vòng sáng càng lớn chứng tỏ khả năng phân giải agar của vi khuẩn càng mạnh.

Sau 2 ngày ủ trên môi trường Marine agar và nhuôm với dung dịch Lugol, đường kính vòng 
Bảng 1. Đặc điểm các dòng vi khuẩn phân giải agar phân lập từ nước biển

\begin{tabular}{cccccc}
\hline STT & Kí hiệu chủng & Nơi phân lập & Đặc điểm khuẩn lạc & Gram & Hình dạng tế bào \\
\hline 1 & M1 & Phước Tĩnh & Trắng ngà & - & Hình que cong \\
2 & M2 & Phước Tĩnh & Trăng ngà & - & Hình que cong \\
3 & M3 & Long Hải & Trắng ngà & - & Hình que cong \\
4 & M4 & Long Hải & Trắng ngà & - & Hình que \\
5 & M5 & Phước Tĩnh & Trăng ngà & - & Hình que cong \\
6 & M6 & Long Hải & Trắng ngà & - & Hình que \\
7 & M7 & Long Hải & Trăng ngà & - & Hình que cong \\
8 & M8 & Phước Tĩnh & Trăng ngà & - & Hình ovan \\
9 & M9 & Phước Tĩnh & Trắng ngà & - & Hình que cong \\
10 & M10 & Phước Tĩnh & Trăng ngà & - & Hình ovan \\
11 & M11 & Long Hải & Trắng đục & - & Hình que cong \\
12 & M12 & Long Hải & Trăng đục & - & Hình que cong \\
13 & M13 & Long Hải & Trăng đục & - & Hình ovan \\
14 & M14 & Long Hải & Trăng đục & - & Hình ovan \\
15 & M61 & Phước Tĩnh & Vàng nhạt & - & Hình que cong \\
16 & M62A & Phước Tĩnh & Vàng nhạt & - & Hình que cong \\
17 & M62B & Phước Tĩnh & Vàng nhạt & - & Hình que cong \\
18 & M71 & Long Hải & Vàng nhạt & - & Hình que cong \\
19 & M72 & Long Hải & Vàng nhạt & - & Hình que \\
20 & M82A & Phước Tĩnh & Vàng nhạt & - & Hình ovan \\
21 & M82B & Phước Tĩnh & Vàng nhạt & - & Hình que cong \\
\hline
\end{tabular}

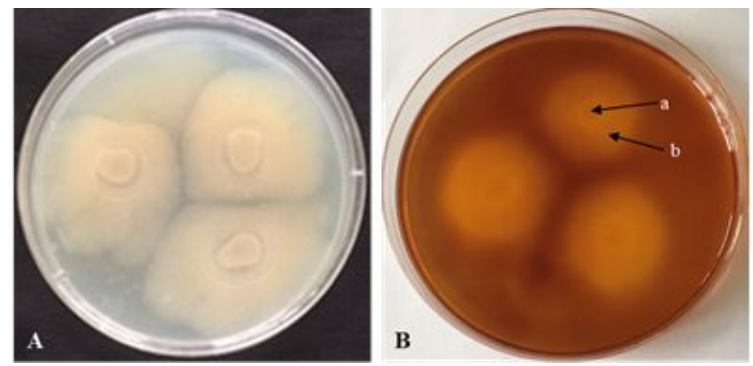

Hình 2. Các vi khuẩn phân giải agar trên đĩa môi trường trước khi nhuộm $(\mathrm{A})$ và sau khi nhuộm $(\mathrm{B})$ với dung dịch Lugol trong đó a là khuẩn lạc vi khuẩn và b là vòng phân giải agar.

phân giải agar của 21 chủng vi khuẩn phân lập được xác định dao động trong khoảng $4-7 \mathrm{~cm}$ (Hình 3). Trong đó, các chủng vi khuẩn kí hiệu M1, M5, M7, M8, M61, M62B, M71, M72, and M82A có đường kính vòng phân giải agar lớn nhất $(7 \mathrm{~cm})$. Việc khảo sát hoạt tính agarase thông qua vòng phân giải agar trên đĩa thạch cũng đã được sử dụng trước đây đối với trên $V i b$ rio sp. F-6 phân lập từ nước biển $(\mathrm{Fu} \mathrm{\&} \mathrm{ctv.,}$ 2008), Micrococcus sp. GNUM-08124 từ rong biển (Choi \& ctv., 2011), Flammeovirga sp. MY04 từ trầm tích biển (Han \& ctv., 2012), V. neocale- donicus và Vibrio azureus từ rong biển (González \& ctv., 2018) và Pseudomonas stutzeri từ nước biển (Kolhatkar \& Sambrani, 2018).

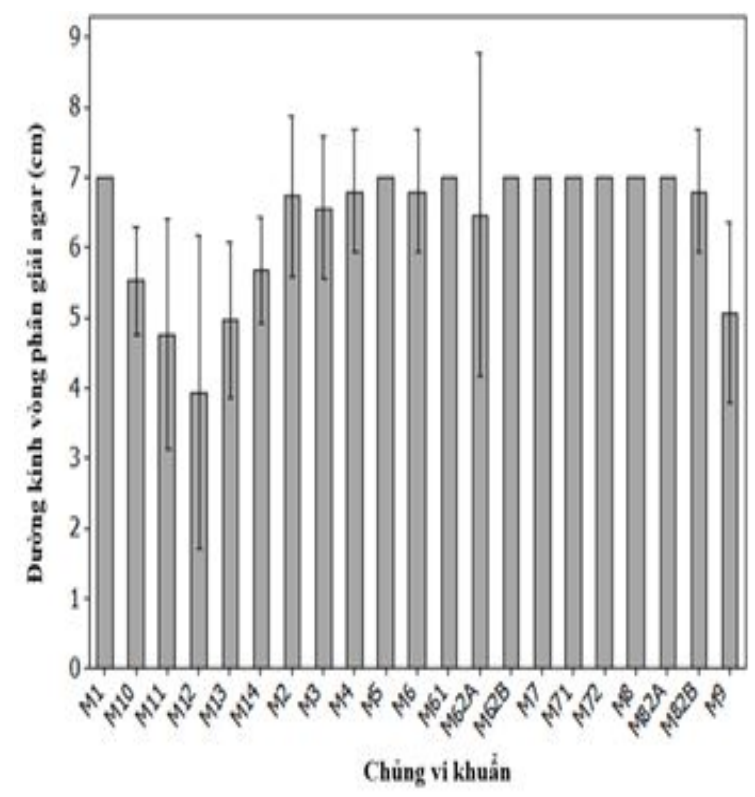

Hình 3. Đường kính vòng phân giải agar của 21 chủng vi khuẩn phân lập sau 2 ngày trên môi trường Marine agar. 


\section{3. Định danh các chủng vi khuẩn có hoạt tính phân giải agar mạnh}

Năm chủng vi khuẩn có hoạt tính phân giải agar mạnh (M1, M5, M7, M62B và M71) được chọn để định danh bằng cách giải trình tự vùng gene $16 \mathrm{~S}$ rRNA và so sánh độ tương đồng với các trình tự đã biết trên ngân hàng gene (Bảng 2). Kết quả cho thấy cả 5 chủng vi khuẩn phân giải agar được tuyển chọn đều tương đồng > $96 \%$ với chi Vibrio. Theo Farmer \& Hickman-Brenner (1992), vi khuẩn thuôc chi Vibrio là những vi khuẩn Gram âm, hình que ngắn hoặc que cong, có mặt khắp nơi trong các môi trường biển. Mặc dù vi khuẩn Vibrio spp. có thể gây bệnh cho người, động vật và các sinh vật biển; tuy nhiên chỉ có giới hạn một số loài như $V$. cholerae, $V$. anguillarum, $V$. harveyi và $V$. ordali được biết là gây bệnh phổ biến (Janda \& ctv., 2015). Các loài Vibrio đã được chứng minh có thể sản xuất nhiều hợp chất ngoại bào có hoạt tính sinh học trong đó có agarase, được ứng dụng trong công nghiệp thực phẩm, dược phẩm, môi trường và sản xuất nhiên liệu sinh học (Fu \& Kim, 2010; Mansson \& ctv., 2011). Đã có nhiều công bố về sự hiện diện của vi khuẩn Vibrio sinh agarase từ trong môi trường biển như nước biển (Macián \& ctv., 2001; Fu \& ctv., 2008), trầm tích (Saravanan \& ctv., 2015) hoặc trên bề mặt các loại rong biển (Lavilla-Pitogo, 1992; González \& ctv., 2018).

\subsection{Hoạt độ enzyme agarase của các chủng vi khuẩn tuyển chọn}

Theo Chi \& ctv. (2012), vi khuẩn sinh enzyme agarase thủy phân cơ chất agarose tạo thành các đường đơn. Do đó, hoạt tính enzyme agarase có thể được định thông qua lượng đường khử được giải phóng khi cho enzyme phản ứng với cơ chất agarose (Faturrahman \& ctv., 2011). Sau phản ứng giữa dịch enzyme thô của 5 chủng vi khuẩn tuyển chọn (M1, M5, M7, M62B và $\mathrm{M} 71)$ với agarose $0,2 \%$ trong 15 phút ở $40^{\circ} \mathrm{C}$, lượng đường khử được giải phóng dao động trong khoảng 0,75 - 1,09 $\mu \mathrm{M} / \mathrm{mL}$ tương ứng với hoạt độ enzyme 0,15 - 0,22 U/mL (Hình 4). Trong đó, chủng M71 cho enzyme agarase có hoạt độ cao nhất khác biệt có ý nghĩa $(P<0,05)$ so với các chủng còn lại.

Trước đây, Saravanan \& ctv. (2015) đã tinh sạch một phần enzyme agarase của vi khuẩn $V i b$ rio sp. phân lập từ nước biển ở Pondicherry (Ấn Độ), và cho phản ứng với cơ chất agar $0,5 \%$ trong 30 phút ở $33^{\circ} \mathrm{C}$ và hoạt độ enzyme đạt 29,7

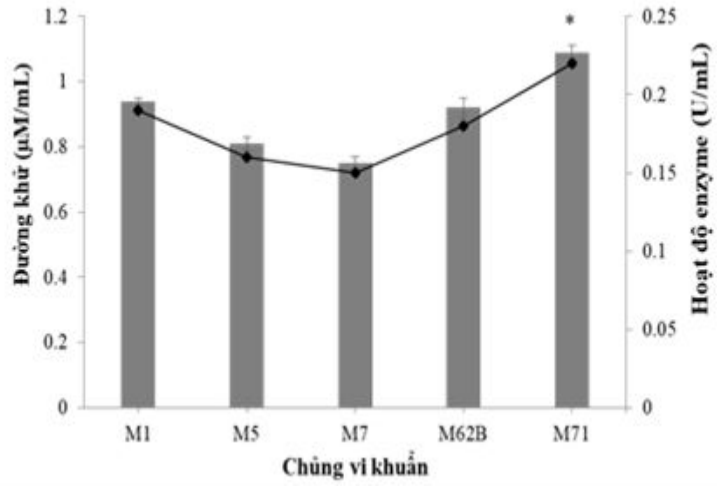

Hình 4. Lượng đường khử tạo ra khi phản ứng với agarose (bar) và hoạt độ enzyme agarase (line) của các chủng vi khuẩn tuyển chọn. *thể hiện sự khác biệt có ý nghĩa $(P<0,05)$.

U/mL. Zeng \& ctv. (2016) báo cáo rằng vi khuẩn Thalassospira profundimonas phân lập từ nước biển ở Trung Quốc sinh enzyme $\beta$-agarase có hoạt độ $0,84 \mathrm{U} / \mathrm{mL}$ khi cho phản ứng với agarose $0,2 \%$ ở $45^{\circ} \mathrm{C}$ trong 30 phút. Tương tự, hoạt độ agarase của các vi khuẩn khác phân lập từ môi trường cũng đã được xác định như Agarivorans albus YKW-34 (khoảng 1,0 U/mL) (Fu \& ctv., 2008), Alteromonas sp. SY37-12 (1,8 U/mL) (Wang \& ctv., 2006), và Vibrio sp. QJH-12 $(1,72 \mathrm{U} / \mathrm{mL})$ (Wang \& ctv., 2004). Như vậy, có thể thấy vi khuẩn phân lập từ các nguồn khác nhau, được nuôi cấy và phản ứng với cơ chất trong điều kiện khác nhau sinh enzyme agarase có hoạt độ khác nhau.

\subsection{Khả năng thủy phân rong biển của chủng vi khuẩn tuyển chọn}

Chủng vi khuẩn M71 ( V. alginolyticus strain YTUY6) có hoạt độ enzyme agarase cao nhất được chọn để đánh giá khả năng thủy phân rong đỏ Gracilaria sp. với nồng độ enzyme sử dụng 5 - 15\% (v/v). Kết quả ở Hình 5 cho thấy, sau 24 giờ ủ ở $40^{\circ} \mathrm{C}$, lượng đường khử được giải phóng cao nhất $(915 \mu \mathrm{M} / \mathrm{mL})$ với nồng độ enzyme $5 \%$. Khi tăng nồng độ enzyme thì lượng đường khử sinh ra càng giảm. Kết quả này tương tự với công bố của Kawaroe \& ctv. (2014) khi sử dụng dịch enzyme agarase thô của vi khuẩn Pseudomonas stutzeri thủy phân rong Gelidium sp. Nồng độ enzyme thích hợp cho sự thủy phân được xác định là $10 \%(\mathrm{v} / \mathrm{v})$, khi tăng nồng độ enzyme lên 15 - $20 \%$ thì lượng đường khử tạo ra càng giảm. Điều này có thể giải thích là do enzyme và cơ 
Bảng 2. Kết quả định danh các chủng vi khuẩn tuyển chọn

\begin{tabular}{clcc}
\hline $\begin{array}{c}\text { Kí hiệu } \\
\text { vi khuẩn }\end{array}$ & Loài xác định & $\begin{array}{c}\text { Độ tương đồng } \\
(\%)\end{array}$ & $\begin{array}{c}\text { Số hiệu } \\
\text { (Assession number) }\end{array}$ \\
\hline M1 & Vibrio neocaledonicus strain CGJ02-2 & 97,77 & CP032213.1 \\
M5 & Vibrio sp. strain ZQM2017 & 97,43 & MG772935.1 \\
M7 & Vibrio alginolyticus strain Xmb044 & 98,11 & KT986170.1 \\
M62B & Vibrio sp. strain 201707CJKOP-Y165 & 97,67 & MG593729.1 \\
M71 & Vibrio sp. TKA 17 & 96,01 & LC385612.1 \\
\hline
\end{tabular}

chất chỉ hoạt động tối ưu ở một nồng độ thích hợp, khi tăng enzyme hoặc cơ chất không những không làm tăng hiệu quả mà còn ức chế phản ứng (Robinson, 2015).

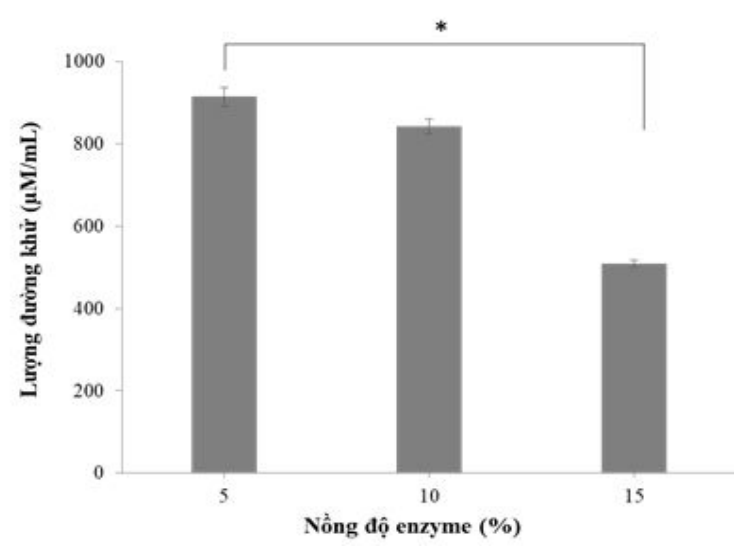

Hình 5. Lượng đường khử được giải phóng khi ủ rong Gracilaria với dịch enzyme agarase thô của chủng vi khuẩn M71. *thể hiện sự khác biệt có ý nghĩa $(P<$ $0,05)$.

Hoạt tính phân giải agar của chủng vi khuẩn tuyển chọn thấp hơn so với các công bố trước như của Wang \& ctv., (2004) và Saravanan \& ctv. (2015) là do trong nghiên cứu này sử dụng dịch enzyme agarase là dịch nuôi cấy vi khuẩn sau khi loại bỏ tế bào, do đó các chất khoáng còn lại trong dịch nuôi cấy có thể ảnh hưởng đến hoạt tính của enzyme (Yang \& ctv., 2019); ngoài ra enzyme chưa được tinh sạch và điều kiện phản ứng thủy phân cơ chất của enzyme agarase chưa được tối ưu cũng có thể là nguyên nhân làm giảm hoạt tính enzyme.

Trong số các loài rong biển được xác định ở Việt Nam thì ngành rong đỏ (Rhodophyta) có sự đa dạng nhất với hơn 400 loài (Nguyen \& ctv., 1993). Trong đó, Gracilaria spp. là một trong các loài rong đỏ có diện tích nuôi cao 10.000 ha, và sản lượng khoảng 4.000 - 5.000 tấn khô/năm (Huynh, 2004). Sinh khối của Gracilaria spp. có chứa hàm lượng lớn carbohydrate dễ phân hủy và đã được sử dụng là nguyên liệu trong sản xuất ethanol sinh học (Kumar \& ctv., 2013). Do đó, kết quả trên cho thấy chủng vi khuẩn M71 có tiềm năng phân giải agar trong thành tế bào của rong đỏ. Cần tinh sạch enzyme agarase cũng như tối ưu điều kiện nuôi cấy và phản ứng để tăng hoạt tính của enzyme agarase của chủng M71.

\section{Kết Luận}

Từ 8 mẫu nước biển thu thập tại tỉnh Bà Rịa Vũng Tàu đã tuyển chọn được 5 chủng vi khuẩn phân giải agar mạnh với đường kính vòng phân giải $7,0 \mathrm{~cm}$, có hoạt độ enzyme agarase thô dao động $0,15-0,22 \mathrm{U} / \mathrm{mL}$ và đều thuộc chi $V i b$ rio với độ tương đồng $>96 \%$. Trong đó, enzyme agarase thô từ chủng vi khuẩn kí hiệu M71 ở nồng độ $5 \%(\mathrm{v} / \mathrm{v})$ có khả năng thủy phân rong Gracilaria giải phóng $915 \mu \mathrm{M} / \mathrm{mL}$ đường khử sau 24 giờ phản ứng.

\section{Lời Cảm Ơn}

Nghiên cứu này là một phần của đề tài khoa học và công nghệ cấp cơ sở mã số CS-CB18CNSH-01 được cấp kinh phí bởi Trường Đại học Nông Lâm TP. Hồ Chí Minh.

\section{Tài Liệu Tham Khảo (References)}

Agbo, J. A. C., \& Moss M. O. (1979). The isolation and characterization of agarolityc bacteria from a Lowland river. Journal of General Microbiology 115, 355-368.

Chi, W. J., Chang, Y. K., \& Hong, S. K. (2012) Agar degradation by microorganisms and agar-degrading enzymes. Applied Microbiology and Biotechnology 94(4), 917-930.

Choi, H. J., Hong, J. B., Park, J. J., Chi, W. J., Kim, M. C., Chang, Y. K., \& Hong S. K. (2011). Production of agarase from a novel Micrococcus sp. GNUM-08124 strain isolated from the east sea of Korea. Biotechnology and Bioprocess Engineering 16, 81-88. 
Farmer, J. J., \& Hickman-Brenner F. W. (1992). The genera vibrio and photobacterium. In Balows, A., Truper, H. G., Dworkin, M., Harder W., \& Schleifer K. H. (Eds.). The Prokaryotes ( $2^{\text {nd }}$ ed., 2952-2301). New York, USA: Springer Verlag.

Faturrahman, Meryandini, A., Junior, M. Z., \& Rusmana, I. (2011). Isolation and identification of an agarliquefying marine bacterium and some properties of its extracellular agarases. Biodiversitas 12, 192-197.

Fu, X. T., \& Kim, S. M. (2010). Agarase: review of major sources, categories, purification method, enzyme characteristics and applications. Marine drugs 8(1), 200218.

Fu, X. T., Lin, H., \& Kim, S. M. (2008). Purification and characterization of a novel $\beta$-agarase, AgaA34, from Agarivorans albus YKW-34. Applied Microbiology and Biotechnology 78, 265-273.

González, N. C., Hoyos, M. L. R., Kleine, L. L., \& Castaño D. M. (2018). Production of enzymes and siderophores by epiphytic bacteria isolated from the marine macroalga Ulva lactuca. Aquatic Biology 27, 107-118.

Han, W., Gu, J., Yan, Q., Li, J., Wu, Z., Gu, Q., \& Li, Y. (2012). A polysaccharide-degrading marine bacterium Flammeovirga sp. MY04 and its extracellular agarase system. Journal of Ocean University of China 11, 375382 .

Huynh, Q. N. (2004). Results of investigation and and production of seaweed in Vietnam, and future orientations. Proceedings of National Conference on research and application of science and technology in aquaculture (559-569). Ha Noi, Vietnam.

Janda, J. M., Newton, A. E., \& Bopp, C. A. (2015). Vibriosis. Clinics in Laboratory Medicine 35, 273-288.

Kawaroe, M., Pratiwi, I., \& Sunudin, A. (2017). Isolation and characterization of marine bacteria from macroalgae Gracilaria salicornia and Gelidium latifolium on agarolitic activity for bioethanol production. IOP Conference Series: Earth and Environmental Science 65, 012025 .

Kawaroe, M., Rusmana, I., \& Nurafni (2014). Production of bioethanol from macroalgae Gelidium sp. using agarase enzymes of marine bacteria. International Journal of Environment and Bioenergy 9(3), 243-251.

Kolhatkar, N., \& Sambrani, S. (2018). Isolation and identification of agar degrading bacteria from marine environment. IOSR Journal of Pharmacy and Biological Sciences 13(3), 1-7.

Kumar, S., Gupta, R., Kumar, G., Sahoo, D., \& Kuhad, R. C. (2013). Bioethanol production from Gracilaria verrucosa, a red alga, in a biorefinery approach. Bioresource Technology 135, 150-156.

Lane, D. J. (1991). 16S/23S rRNA sequencing. In Stackebrandt, E., and Goodfellow, M. (Eds.). Nucleic acid techniques in bacterial systematics (115-176). New York, NY: John Wiley.
Lavilla-Pitogo, C. R. (1992). Agar-digesting bacteria associated with 'rotten thallus syndrome' of Gracilaria sp. Aquaculture 102(1-2), 1-7.

Liu, Y., Tian, X., Peng, C., \& Du, Z. (2019). Isolation and characterization of an eosinophilic GH $16 \beta$-agarase (AgaDL6) from an agar-degrading marine bacterium Flammeovirga sp. HQM9. Journal of Microbiology and Biotechnology 29(2), 235-243.

Macián, M. C., Ludwig, W., Schleifer, K. H., Pujalte, M. J., \& Garay, E. (2001). Vibrio agarivorans sp. nov., a novel agarolytic marine bacterium. International Journal of Systematic and Evolutionary Microbiology 51, 2031-2036.

Mansson, M., Gram, L., \& Larsen, T. O. (2011). Production of bioactive secondary metabolites by marine Vibrionaceae. Marine Drugs 9, 1440-1468.

Miller, G. L. (1959). Use of dinitrosalicylic acid reagent for determination of reducing sugar. Analytical Chemistry 31(3), 426-428.

Nguyen, H. D., Huynh, Q. N., Tran N. B., \& Nguyen, V. T. (1993). Marine algae of North Vietnam. Ha Noi, Vietnam: Science and Technics Publishing House.

Oh, C., Nikapitiya, C., Lee, Y., Whang, I., Kang, D. H., Heo, S. J., Choi, Y. U., \& Lee, J. (2010). Molecular cloning, characterization and enzymatic properties of a novel $\beta$-agarase from a marine isolate Pseudoalteromonas sp. Ag52. Brazilian Journal of Microbiology $41,876-889$

Rioux, L. E., \& Turgeon, S. L. (2015). Seaweed carbohydrates. In Tiwari, B. K., \& Troy D. J. (Eds.). Seaweed sustainability: Food and non-food applications (141192). Massachusetts, USA: Academic Press.

Robinson, P. K. (2015). Enzymes: principles and biotechnological applications. Essays in biochemistry 59, 1-41.

Saravanan, D., Kumar, V. S., \& Radhakrishnan, M. (2015). Isolation and optimization of agarase producing bacteria from marine sediments. International Journal of ChemTech Research 8(4), 1701-1705.

Thulasidas, S. (2012). Isolation and characterization of agarolytic microorganisms and purification of an extracellular enzyme agarase. International Journal of Pharmaceutical \& Biological Archives 3(4), 965-968.

Usov, A. I. (2011). Polysaccharides of the red algae. Advances in Carbohydrate Chemistry and Biochemistry $65,115-217$.

Wang, J., Jiang, X., Mou, H., \& Guan, H. (2004). Antioxidation of agar oligosaccharides produced by agarase from a marine bacterium. Journal of Applied Phycology 16, 333-340.

Wang, J. X., Mou, H. J., Jiang, X. L., \& Guan, H. S. (2006). Characterization of a novel $\beta$-agarase from marine Alteromonas sp. SY37-12 and its degrading products. Applied Microbiology and Biotechnology 71, 833839 . 
Yanagisawa, M., Kawai, S., \& Murata, K. (2013). Production of high concentrations of bioethanol from seaweeds. Bioengineered 4, 224-235.

Yang, Z., Liao, Y., Fu, X., Zaporski, J., Peters, S., Jamison, M., Liu, Y., Wullschleger, S. D., Graham, D. E., \& Gu, B. (2019). Temperature sensitivity of mineral-enzyme interactions on the hydrolysis of cellobiose and indican by $\beta$-glucosidase. Science of The Total Environment 686, 1194-1201.
Zhang, C., \& Kim, S. K. (2008). Research and application of marine microbial enzymes: Status and prospects. Marine Drugs 8, 1920-1934.

Zeng, C., Zhang, L., Miao, S., Zhang, Y., Zeng, S., \& Zheng, B. (2016). Preliminary characterization of a novel $\beta$-agarase from Thalassospira profundimonas. SpringerPlus 5(1), 1-8. 